\title{
A study on family function status and its influencing factors of frontline health workers fighting Novel Coronavirus Disease (COVID-19)
}

\author{
Liqiong Tao ${ }^{1, \dagger}$, Wenjie $\mathrm{Xu}^{1, \dagger}$, Jia Zhang ${ }^{1}$, Xuezhi Hu ${ }^{1, \star}$, Li Sun ${ }^{1, \star}$ \\ ${ }^{1}$ Cancer Center, Union Hospital, Tongji Medical College, Huazhong University of Science and Technology, 430022 Wuhan, China
}

*Correspondence: Sunlixh@outlook.com (Li Sun); 1401037217@qq.com (Xuezhi Hu)

$\dagger$ These authors contributed equally.

\begin{abstract}
Objective: To understand the family function, psychological status, and influencing factors of the family members of the frontline medical staff fighting COVID-19.

Methods: A psychological questionnaire survey was conducted on the families of 189 clinical front line medical staff who participated in the fight against COVID-19 by using the general information questionnaire, the fam- ily care index scale (APGAR), the generalized anxiety scale (GAD-7), and the depression screening scale (PHQ-9), and the influencing factors were analyzed.

Results: The score of family function was 7.00 (5.00, 10.00), 105 individuals (55.6\%) had good family function, 72 individuals (38.1\%) had moderate family dysfunction, and 12 of them (6.3\%) had severe family dysfunction. Multiple linear regression analysis showed that gender, age, educational background, working status during the epidemic, and anxiety level were the influencing factors of the family function status of frontline medical staff $(p<0.05)$.

Conclusion: The family function of the medical staff participating in the clinical frontline fight against COVID-19 is at a medium level. Gender, age, educational background, working status during the epidemic, and anxiety level are the influencing factors of the family function status of this group. The family members of medical personnel have a certain extent of anxiety and depression, so the nursing manager should improve the family function and relieve them of anxiety and depression through psychological counseling and humanistic care, so as to improve their family function.
\end{abstract}

\section{Keywords}

COVID-19; Medical staff; Family functions; Psychological status

\section{Introduction}

The novel coronavirus disease (COVID-19) is a public health incident that poses a huge threat to human life and health. As a main force in the treatment of COVID-19, medical personnel have played a key role in the prevention and control of the epidemic $[1,2]$. When medical workers went to the front line, their families were deeply affected by the changes and they faced great challenges both physically and mentally [2, 3]. Studies have shown that family is an important element of a society and the main source of material and spiritual support for their members [4, 5]. Good family function is of great significance to the growth and development of family members, and has a positive effect on the mental health of family members $[4,6]$. By regulating the functional status of individuals' family, their mental health can be effectively improved [7]. In the fight against COVID-19, physical and mental health of frontline medical staff would be indirectly affected by their family relationships and family support. Therefore, in order to ensure that clinical medical personnel fighting against COVID-19 complete rescue tasks successfully, understanding their family functions and the 
psychological status of their family members is of great significance to improving the ability and enthusiasm of medical workers to deal with COVID-19 circumstances. Only few studies have deliberately studied the functional status and the psychological status of first-line health staff and their family members during the outbreak of COVID-19. This study aims to explore the family functions and the psychological status of the family members of first-line medical staff who fight against COVID-19 from the aspects of family care index, anxiety level, and depression level. This study also provides the basis theory for nursing management department who can take measures to protect health workers' physical and mental health and the report is as follows.

\section{Objects and methods}

\subsection{Research objects}

We selected 189 cases of clinical first-line medical staff's families in designated hospitals as the research objects and a questionnaire survey was conducted from March 1 to March 5, 2020. Inclusion criteria: (1) family members of medical staff (resulting in clinical frontline work time of 1 week or more; family members refer to spouses, parents, children, and other close relatives living together) involved in the treatment of those who are diagnosed or suspected of COVID-19; (2) those who are proficient in using mobile phones or computers; (3) personnel voluntarily participating in this study with informed consent. Exclusion criteria: family members of nonworking clinical medical staff, including those on maternity leave, sick leave, vacation, and so on.

\subsection{Research methods}

\subsubsection{Survey tools}

General information questionnaire. We designed general information questionnaires that may affect the family function and the psychological status of family members of firstline medical staff during the epidemic, including gender, age, education, occupation, fertility, medical staff position, health status during the epidemic, whether family income is affected, whether the main caregivers of the child have changed, the working status, whether they live with the firstline medical staff during the epidemic, and the problem that most troubles family members since entering the first-line work by consulting relevant literature.

Family care index questionnaire. The family care Index questionnaire (family adaptation, partnership, growth, affection and resolve, and F-APGAR scale) designed by Smikstein at the University of Washington was used to evaluation. The Chinese version of the F-APGAR questionnaire has been reported as a reliable tool; its Cronbach's $\alpha$ coefficient is 0.80-0.83, with good reliability [8]. F-APGAR has a total of five items including fitness, cooperation, growth length, affection, and intimacy. Each project consists of one item and each item corresponds to one question, with a threelevel score. Points of each item is assigned 0 (never), 1 (sometimes), and 2 (often). A total score of 7-10 points indicate good family function, 4-6 points indicate moderate family function disorder, and 0-3 points indicate severe family function disorder.

Depression screening scale (PHQ-9). The depression symptoms scale (patient health questionnaire 9, PHQ-9) is based on nine criteria for depression in the Diagnostic and Statistical Manual of Mental Disorders published by the American Psychiatric Association, and is very sensitive to changes in depressive symptoms [9]. It consists of nine items, each item is $0-3$ points, the total score is $0-27$ points. Among them, 0 means no, and 3 means almost every day. Scoring standard: 0-4 is categorized as no depression; 5-9 is categorized as mild depression; 10-14 is categorized as moderate depression; $15-$ 19 is categorized as moderate and severe depression, 20-27 is categorized as severe depression. Studies have shown that the PHQ-9 Cronbach's $\alpha$ coefficient is 0.89 [10].

General anxiety scale (GAD-7). Generalized Anxiety Disorder 7 (GAD-7) is a quantitative evaluation standard recommended by the fifth edition of the Diagnostic and Statistical Manual of Mental Disorders published by the American Psychiatric Association, and is used to identify possible cases of generalized anxiety disorder [11]. Effective tool, composed of 7 items, each item is $0-3$ points, the total score is $0-21$ points. A score of 0 means nothing at all, and a score of 3 means it happens almost every day. Scoring standard: $0-4$ is classified as no anxiety mood; 5-9 is classified as mild anxiety; $10-14$ is classified as moderate anxiety; $15-21$ points or more is classifies as severe anxiety. It has shown good reliability and validity in previous research. The Cronbach's $\alpha$ coefficient of the Chinese version of the scale is 0.849 .

\subsubsection{Data collection methods}

The Questionnaire Star (a Chinses questionnaire statistics website) is used to collect data in a unified manner and the questionnaire link is https://www.wjx.cn/m/ 71391276.aspx. On the WeChat platform (A Chinese social platform), the investigators explained this to the research subjects who met the inclusion and exclusion criteria. After obtaining the informed consent of the research subjects, the investigator explained the contents and filling requirements of the questionnaire to them. They completed filling the questionnaire independently after understanding and the investigation process followed the principle of confidentiality. In this survey, a total of 200 family members of clinical frontline medical personnel, who partook in the fight against COVID-19, participated. Among them, 189 filled valid questionnaires and the effective recovery rate was $94.5 \%$.

\subsubsection{Statistical methods}

Excel 2010 software was used for data collation and they were double-checked. SPSS 25.0 software was used to analyze the data, frequency and composition ratio were used to describe the count data, M (P25, P75) was used to describe the non-normally distributed measurement data, and the Mann-Whitney U-test or Kruskal-Wallis test was used to compare the family function scores. Spearman test was used 
T A B L E 1. Family functional status of first-line medical personnel fighting COVID-19.

\begin{tabular}{lccc}
\hline Items & Cases & Ratio (\%) & Family function score $\left[\mathrm{M}\left(\mathrm{P}_{25}, \mathrm{P}_{75}\right)\right]$ \\
\hline All & & & $7.00(5.00,10.00)$ \\
Grade & & & \\
$\quad$ Good & 105 & 55.6 & $9.00(8.00,10.00)$ \\
$\quad$ Moderate disorder & 72 & 38.1 & $5.00(4.25,5.00)$ \\
$\quad$ Severe disorder & 12 & 6.3 & $1.00(0.00,2.75)$ \\
\hline
\end{tabular}

for correlation analysis and multiple linear regression analysis was used for multi-factor analysis; $p<0.05$ was considered statistically significant.

\section{Results}

\subsection{Family functional status of first-line medical staff who fought against COVID-19}

The scores of 189 cases of first-line medical staff family functional status were $7.00(5.00,10.00)$. The scores of the five dimensions of fitness, cooperation, adult length, affection, and intimacy were $1.00(1.00,2.00)$ point, $2.00(1.00,2.00)$ points, $2.00(1.00,2.00)$ points, $2.00(1.00,2.00)$ points, and $1.00(1.00,2.00)$ point (Table 1$)$.

\subsection{Psychological status of family members of frontline medical personnel who fought against COVID-19}

The median scores of anxiety and depression of family members of frontline medical staff fighting COVID-19 were 8.00 $(6.00,14.00)$ and $9.00(5.00,14.00)$, respectively. According to the scoring criteria, 48 people (25.4\%) did not have anxiety, and there were 63 (33.3\%), 51 (27\%), and 27 (14.3\%) family members of first-line medical staff with mild, moderate, and severe anxiety. Although, 54 individuals (28.6\%) did not have depression, 57 (30.2\%), 42 (22.2\%), 27 (14.3\%), and 9 (accounting for $4.8 \%$ ) family members were identified with mild, moderate, medium severe, and severe depression.

\subsection{Single factor analysis of family function status of first-line medical staff who fought against COVID-19}

The results of the study showed that there was a statistically significant difference in family function scores across different genders, ages, educational backgrounds, occupations, work status, and whether they lived with frontline medical staff during the epidemic or not $(p<0.05)$ (Table 2).

\subsection{Correlation analysis of family function and anxiety and depression of first-line medical staff fighting COVID-19}

Using Spearman correlation analysis indicated that the total score of family function and the total score of anxiety are negatively correlated $(\mathrm{r}=-0.314, p=0.000)$. The total score of family function was negatively correlated with the total score of depression $(\mathrm{r}=-0.368, p=0.000)$.

\subsection{Multi-factor analysis of family function status of frontline medical personnel fighting COVID-19}

Take the total score of family function as the dependent variable and use single-factor analysis and correlation analysis to have statistically significant variables as independent variables for multiple linear regression analysis $(\alpha$ in $=0.05$, $\alpha$ out $=0.01)($ Table 3$)$.

\section{Discussion}

This study analyzed the changes in family status and social functions brought about by the fact that one of the family members was a medical staff during the prevalence of COVID-19. These changes are often caused by the lack of kinship, the decrease of salary, and the increase of workload, which varies with gender and education level.

COVID-19 affects the physical and mental health of almost all the population, especially in the case of frontline medical workers who have to cope with the decline of family function [12]. Coping with the epidemic of COVID-19 is not only faced with the huge risk of infectious diseases, but also by the collapse of the medical system caused by a large number of patients [13]. Wijeratne et al. [14] reported that the current diagnosis rates of depression among young doctors, middle-aged doctors, and elderly doctors were 8.52, 7.51, and $4.38 \%$, respectively. This was far lower than our results, indicating that COVID-19 has a great impact on doctors' mental health. In China, many frontline medical workers live separately from their families during the outbreak to reduce the potential for infection among their families. In our study, $60.3 \%$ of family members (wife or husband) lived separately from frontline medical workers, which greatly reduced the contact time between doctors and family members. Close contact with family members is a necessary condition to enhance family feelings [15]. Longer shared family time can improve the relationship within the family; promoting the mental health of family members and reducing the degree of depression [16]. Depression patients are often accompanied by varying degrees of work capacity loss [17]. The lack of parental affection and the reduction of communication with parents (usually when the medical workers are parents) will also significantly affect the physical and mental development of children [18] because parent-child interaction is an important regulatory way to support children's continuous development [19]. However, the disharmony of family relationship will aggravate individuals' depression [20].

COVID-19 has also led to a global economic downturn, higher unemployment, and lower wages [21]. This research 
T A B L E 2. Comparison of family functions of first-line medical staff with different characteristics against COVID-19.

\begin{tabular}{|c|c|c|c|c|c|}
\hline Variable of interest & Cases & Rato (\%) & Family function score & Statistic value & $p$ value \\
\hline \multicolumn{6}{|l|}{ Gender } \\
\hline Male & 99 & 52.4 & $6.00(5.00,9.00)$ & & \\
\hline Female & 90 & 47.6 & $8.00(5.00,10.00)$ & $-3.842^{\mathrm{a}}$ & 0.000 \\
\hline \multicolumn{6}{|l|}{ Age } \\
\hline$\leq 20$ & 3 & 1.6 & $7.00(7.00,7.00)$ & & \\
\hline $21-30$ & 27 & 14.3 & $5.00(5.00,7.00)$ & & \\
\hline $31-40$ & 87 & 46 & $6.00(4.00,10.00)$ & & \\
\hline$\geq 40$ & 72 & 38.1 & $8.00(6.25,10.00)$ & $9.384^{\mathrm{b}}$ & 0.025 \\
\hline \multicolumn{6}{|l|}{ Educational background } \\
\hline Junior high school and below & 9 & 4.8 & $8.00(7.00,10.00)$ & & \\
\hline High school & 21 & 11.1 & $10.00(7.00,10.00)$ & & \\
\hline Technical secondary school & 9 & 4.8 & $5.00(5.00,7.00)$ & & \\
\hline College & 30 & 15.9 & $6.00(5.00,9.00)$ & & \\
\hline Undergraduate & 111 & 58.7 & $7.00(4.00,9.00)$ & & \\
\hline Master degree and above & 9 & 4.8 & $7.00(7.00,10.00)$ & $16.901^{\mathrm{b}}$ & 0.005 \\
\hline \multicolumn{6}{|l|}{ Occupation } \\
\hline Teachers & 6 & 3.2 & $8.00(7.00,9.00)$ & & \\
\hline Students & 3 & 1.6 & $7.00(7.00,7.00)$ & & \\
\hline Professional skill workers & 54 & 28.6 & $5.00(4.00,7.00)$ & & \\
\hline Civil servant & 6 & 3.2 & $10.00(10.00,10.00)$ & & \\
\hline workers & 9 & 4.8 & $10.00(7.00,10.00)$ & & \\
\hline Farmers & 6 & 3.2 & $10.00(10.00,10.00)$ & & \\
\hline Freelancers & 42 & 22.2 & $6.00(5.00,9.00)$ & & \\
\hline Soldiers & 3 & 1.6 & $9.00(9.00,9.00)$ & & \\
\hline Medical workers & 54 & 28.6 & $8.500(5.00,10.00)$ & & \\
\hline others & 6 & 3.2 & $7.00(7.00,7.00)$ & $47.961^{\mathrm{b}}$ & 0.000 \\
\hline \multicolumn{6}{|l|}{ Health during the outbreak } \\
\hline Health & 135 & 71.4 & $7.00(5.00,7.00)$ & & \\
\hline Good & 34 & 15.9 & $7.00(5.00,8.00)$ & & \\
\hline General & 20 & 12.7 & $6.50(5.00,9.75)$ & $0.726^{\mathrm{b}}$ & 0.696 \\
\hline \multicolumn{6}{|c|}{ Whether income was affected during the epidemic or not } \\
\hline Yes & 156 & 82.5 & $6.50(5.00,10.00)$ & & \\
\hline No & 33 & 17.5 & $7.00(7.00,9.00)$ & $-0.385^{\mathrm{a}}$ & 0.700 \\
\hline \multicolumn{6}{|l|}{ Fertility } \\
\hline No kids & 30 & 15.9 & $5.00(5.00,7.00)$ & & \\
\hline Have kid, 1 & 114 & 60.3 & $7.00(5.00,10.00)$ & & \\
\hline Have kids, 2 & 36 & 19 & $7.00(5.00,10.00)$ & & \\
\hline Have kids, $\geq 3$ & 9 & 4.8 & $9.00(8.00,10.00)$ & $6.876^{\mathrm{b}}$ & 0.076 \\
\hline \multicolumn{6}{|c|}{ Was the primary caregiver of the child during the outbreak } \\
\hline Yes & 102 & 53.9 & $6.50(5.00,8.75)$ & & \\
\hline No & 87 & 46.1 & $7.00(5.00,10.00)$ & $-1.623^{\mathrm{a}}$ & 0.105 \\
\hline \multicolumn{6}{|l|}{ Working status during the epidemic } \\
\hline Rest & 72 & 38.1 & $6.50(5.00,10.00)$ & & \\
\hline Home & 63 & 33.3 & $6.00(5.00,8.00)$ & & \\
\hline Company & 54 & 28.6 & $9.00(7.00,10.00)$ & $16.041^{\mathrm{b}}$ & 0.000 \\
\hline \multicolumn{6}{|l|}{ Live with frontline medical staff } \\
\hline Yes & 75 & 39.7 & $5.00(5.00,10.00)$ & & \\
\hline No & 114 & 60.3 & $7.50(5.00,10.00)$ & $-2.341^{\mathrm{a}}$ & 0.019 \\
\hline \multicolumn{6}{|l|}{ Anxiety level } \\
\hline No & 48 & 25.4 & $10.00(7.00,10.00)$ & & \\
\hline Mild & 63 & 33.3 & $7.00(5.00,9.00)$ & & \\
\hline Moderate & 51 & 27 & $5.00(5.00,7.00)$ & & \\
\hline Severe & 27 & 14.3 & $7.00(4.00,9.00)$ & $34.248^{\mathrm{b}}$ & 0.000 \\
\hline \multicolumn{6}{|l|}{ Depression level } \\
\hline No & 54 & 28.6 & $9.50(75.00,10.00)$ & & \\
\hline Mild & 57 & 30.2 & $6.00(5.00,9.00)$ & & \\
\hline Moderate & 42 & 22.2 & $6.00(4.00,9.00)$ & & \\
\hline Medium severe & 27 & 14.3 & $5.00(5.00,6.00)$ & & \\
\hline Severe & 9 & 4.8 & $8.00(4.00,9.00)$ & $22.853^{\mathrm{b}}$ & 0.000 \\
\hline
\end{tabular}

Note: ${ }^{\mathrm{a}}$ is $\mathrm{Z}$ value, ${ }^{\mathrm{b}}$ is $\mathrm{K}$ value. 
T A B L E 3. Multiple linear regression analysis of the family function status of first-line medical personnel fighting against COVID-19 ( $n=189)$.

\begin{tabular}{lccccc}
\hline Variable & B value & SE & Standard partial regression coefficient & $\mathrm{t}$ & \multicolumn{1}{c}{$p$} \\
\hline Constant & 4.711 & 1.490 & - & 3.162 & 0.002 \\
Gender & 1.537 & 0.460 & 0.300 & 3.419 & 0.001 \\
Age & 0.659 & 0.226 & 0.185 & 2.917 & 0.004 \\
Educational background & -0.429 & 0.139 & -0.209 & -3.081 & 0.002 \\
Occupation & -0.089 & 0.090 & -0.091 & -0.988 & 0.324 \\
Working status & 0.417 & 0.353 & 0.078 & 1.179 & 0.000 \\
Live with frontline medical staff & 0.887 & 0.219 & 0.274 & 4.040 & 0.240 \\
Anxiety level & -0.917 & 0.258 & -0.350 & -3.554 & 0.000 \\
Depression level & -0.051 & 0.216 & -0.023 & -0.234 & 0.815 \\
\hline
\end{tabular}

Note: $\mathrm{R}=0.578, \mathrm{R}^{2}=0.334$, adjust $\mathrm{R}^{2}=0.305 ; \mathrm{F}=11.302, p<0.000$.

* In order to prevent the possibility of infection in family members, some front-line workers will choose not to live with their families during the epidemic period.

also confirms the stance, with more than $80 \%$ of household income affected during the outbreak. Income is the most important factor affecting family happiness. Some studies have pointed out that the happiness index of middle-class families is significantly higher than that of low-income families [22, 23]. The decline of income will affect the mental health of any group $[24,25]$. People with low economic ability are more likely to suffer from mental disorders, leading to events such as suicide [24, 25]. Moreover, COVID-19 will increase the gap of social wealth distribution, resulting in unfairness and social instability [26].

The overload of medical system caused by the epidemic also led to the decline of family function of health guardian. Portoghese et al. [27] pointed out that overwork will lead to work fatigue of medical workers, which is the most important factor affecting the physical and mental health of medical workers. Furthermore, studies have shown that during the prevalence of COVID-19, the working hours of medical workers are positively correlated with the degree of depression [13]. Overwork will also lead to the decline of individuals' ability to bear, and then lead to insomnia, anxiety, even suicide, and other such behaviors, leading to the decline of social function [13]. Other studies have shown that there is a certain correlation between family function and job burnout $[28,29]$. Overwork often leads to disharmony within the family $[28,29]$. Therefore, we must pay more attention to the mental health of medical workers and their families.

Education level also affects individuals' tolerance to stress. In this study, the family function scores of first-line medical personnel family members with technical secondary education were low. It may be that their independent thinking ability is not as good as that of a highly educated person [30] and the ability to adopt different behavior control modes in different situations is even worse [31]. Anker et al. [12] point out that the higher the level of education, the lower the risk of mental illness for individuals, which illustrates this standpoint.

As for family members who work at home, their family function score is low, which may be due to the need to take care of family and work at the same time as they are working at home. Human beings are social animals, whose psychological development cannot be separated from social communication. Longtime solitude will lead to the degradation of social functions [32]. Working at home will reduce the unnecessary communication with colleagues and customers to a certain extent; however, these interactions often help to sooth the anxiety and fear of individuals. The way of working remotely at home aggravates the work fatigue and pressure, and also leads to alienation of social relations, which is not conducive to the maintenance of family function [33]. Therefore, managers should pay more attention to good communication with medical staff and their families. Not only should they reduce or eliminate the factors that cause medical staff burnout in the working environment, but also they should do something necessary to supporting their family, and necessary social communication. As a result, this can improve the enthusiasm of clinical frontline medical staff.

The limitation of this study is that the results were collected online and it was unable to get more detailed information of influencing factors through face-to-face communication. In the design of the questionnaire, predominant focus was on the individuals' evaluation of depression; their symptoms were not collected to quantitatively and reasonably evaluate their psychological defects. Therefore, in view of the shortcomings of our experiment, a retrospective study should be carried out to explore the impact of the epidemic on the mental health of the frontline staff of health guardians.

\section{Conclusions}

A family can provide physical support and spiritual support. Good family function is the condition of such support so family function is an important factor that directly affects the health of the medical staff. As a family member of clinical first-line medical staff, they must face the problems of the serious epidemic and this threatened their life, at the same time they have to bear the pressure of various aspects of family work caused by sudden changes. The mental health of frontline medical staff may also be affected by the behavior of family members.

Study on the status of first-line medical staff's family func- 
tions and analysis of their influencing factors are rare. Exploring the status of life of family members of first-line medical staff, understanding their emotional state of mind, existing physiological and psychological problems, and expectations can provide clinical managers with a practical and reliable basis to formulate humanized measures.

\section{Author contributions}

Conceptualization, LS and XH; methodology, LT, WX; software, JZ; validation, LT; formal analysis, WX; investigation, LT and LS; data curation, WX; writing-original draft preparation, LT, WX; writing-review and editing, XH, LT; supervision, JZ, WX. All authors have read and agreed to the published version of the manuscript.

\section{Ethics approval and consent to participate}

Investigation has been conducted in accordance with the ethical standards and according to the Declaration of Helsinki and national and international guidelines.

\section{Acknowledgment}

Not application.

\section{Funding}

The research received no funding.

\section{Conflict of interest}

The authors declare no conflict of interest.

\section{References}

[1] Liu Q, Luo D, Haase JE, Guo Q, Wang XQ, Liu S, et al. The experiences of health-care providers during the COVID-19 crisis in China: a qualitative study. The Lancet Global Health. 2020; 8: e790-e798.

[2] Bansal P, Bingemann TA, Greenhawt M, Mosnaim G, Nanda A, Oppenheimer J, et al. Clinician Wellness during the COVID-19 Pandemic: Extraordinary Times and Unusual Challenges for the Allergist/Immunologist. The Journal of Allergy and Clinical Immunology: in Practice. 2020; 8: 1781-1790.e3.

[3] Clark DW. The physician and the family. Public Health Reports. 1956; 71: 1022-1024.

[4] Chen E, Brody GH, Miller GE. Childhood close family relationships and health. The American Psychologist. 2018; 72: 555-566.

[5] Sottile PD, Lynch Y, Mealer M, Moss M. Association between Resilience and Family Member Psychologic Symptoms in Critical Illness. Critical Care Medicine. 2017; 44: e721-e727.

[6] García-Huidobro D, Puschel K, Soto G. Family functioning style and health: opportunities for health prevention in primary care. the British Journal of General Practice. 2012; 62: e198-e203.

[7] Reinares M, Vieta E, Colom F, Martínez-Arán A, Torrent C, Comes M, et al. Impact of a Psychoeducational Family Intervention on Caregivers of Stabilized Bipolar Patients. Psychotherapy and Psychosomatics. 2004; 73: 312-319.

[8] Chen Y, Chen S, Gau SS. ADHD and autistic traits, family function, parenting style, and social adjustment for Internet addiction among children and adolescents in Taiwan: a longitudinal study. Research in Developmental Disabilities. 2015; 39: 20-31.

[9] Kroenke K, Spitzer RL. The PHQ-9: a New Depression Diagnostic and Severity Measure. Psychiatric Annals. 2002; 32: 509-515.
[10] Seo J, Park S. Validation of the Patient Health Questionnaire-9 (PHQ9 ) and PHQ-2 in patients with migraine. The Journal of Headache and Pain. 2015; 16: 65 .

[11] Spitzer RL, Kroenke K, Williams JBW, Löwe B. A Brief Measure for Assessing Generalized Anxiety Disorder. Archives of Internal Medicine. 2006; 166: 1092

[12] Cash JL, Christian AR, Greaves DR. Chemerin peptides promote phagocytosis in a ChemR23- and Syk-dependent manner. Journal of Immunology. 2010; 184: 5315-5324.

[13] Zhou Y, Wang W, Sun Y, Qian W, Liu Z, Wang R, et al. The prevalence and risk factors of psychological disturbances of frontline medical staff in china under the COVID-19 epidemic: Workload should be concerned. Journal of Affective Disorders. 2020; 277: 510514

[14] Wijeratne C, Johnco C, Draper B, Earl JK. Older Physicians' Reporting of Psychological Distress, Alcohol Use, Burnout and Workplace Stressors. The American Journal of Geriatric Psychiatry. 2020; 29: 478-487.

[15] Pizarro KW, Surkan PJ, Bustamante IV. The Social Ecology of Parental Monitoring: Parent-Child Dynamics in a High-Risk Peruvian Neighborhood. Family Process. 2020; 60: 199-215.

[16] Barton AW, Lavner JA, Beach SRH. Can Interventions that Strengthen Couples' Relationships Confer Additional Benefits for their Health? a Randomized Controlled Trial with African American Couples. Prevention Science. 2020; 22: 386-396.

[17] Nagata T, Fujino Y, Ohtani M, Fujimoto K, Nagata M, Kajiki S, et al. Work functioning impairment in the course of pharmacotherapy treatment for depression. Scientific Reports. 2020; 10: 15712.

[18] Pancsofar N, Vernon-Feagans L. Mother and father language input to young children: Contributions to later language development. Journal of Applied Developmental Psychology. 2006; 27: 571-587.

[19] Wang H, Suveg C, West KB, Han ZR, Zhang X, Hu X, et al. Synchrony of Respiratory Sinus Arrhythmia in Parents and Children with Autism Spectrum Disorder: Moderation by Interaction Quality and Child Behavior Problems. Autism Research. 2020; 14: 512-522.

[20] Zhou M, Zhang J, Li F, Chen C. Work-family conflict and depressive symptoms among Chinese employees: Cross-level interaction of organizational justice climate and family flexibility. International Journal of Environmental Research and Public Health. 2020; 17: 69546917.

[21] Otugo O, Wages B. COVID-19: the Additional Sentence for the Incarcerated. Health Equity. 2020; 4: 403-405.

[22] Putnam-Farr E, Morewedge CK. Which social comparisons influence happiness with unequal pay? Journal of Experimental Psychology: General. 2020.

[23] Mutumba M, Schulenberg J. Cross-national variation in the subjective wellbeing of youth in low and middle income countries: the role of structural and micro-level factors. Journal of Youth Studies. 2020; 23 252-268.

[24] Patel V. Income Inequality and Psychiatric Admission in a Rich Country: Happiness does not Guarantee Mental Health Equity. JAMA Psychiatry. 2020; 77: 233.

[25] Song A, Kim W. The association between relative income and depressive symptoms in adults: Findings from a nationwide survey in Korea. Journal of Affective Disorders. 2020; 263: 236-240.

[26] Kaur M, Goyal P, Goyal M. Individual, interpersonal and economic challenges of underemployment in the wake of COVID-19. Work. 2020; 67: 21-28

[27] Portoghese I, Galletta M, Coppola RC, Finco G, Campagna M. Burnout and workload among health care workers: the moderating role of job control. Safety and Health at Work. 2014; 5: 152-157.

[28] Montgomery AJ, Panagopolou E, Benos A. Work-family interference as a mediator between job demands and job burnout among doctors. Stress and Health. 2006; 22: 203-212.

[29] Ensle KM. Burnout: How does extension balance job and family? J Extension. 2005; 43: 1-15.

[30] Lipman M. Thinking in education. UK, Cambridge: Cambridge University Press. 2003 
[31] Monteiro S, Ferreira JA, Almeida LS. Self-perceived competency and self-perceived employability in higher education: the mediating role of career adaptability. Journal of further and Higher Education. 2018; 44: 408-422.

[32] Henrich J, Muthukrishna M. The Origins and Psychology of Human
Cooperation. Annual Review of Psychology. 2020; 72: 207-240.

[33] Venegas Tresierra CE, Leyva Pozo AC. Fatigue and mental workload among workers: About social distancing. Revista Española de Salud Pública. 2020; 94. 